\title{
Learning by Experimentation: The Calculatora Estatística Visual
}

\author{
http://dx.doi.org/10.3991/ijoe.v9iS8.3382 \\ Liliane S. Machado, Ronei M. Moraes, Elaine A.M.G. Soares \\ Federal University of Paraíba, João Pessoa/PB, Brazil
}

\begin{abstract}
Learning from experimentation is the basis of the pedagogical theory called Constructivism. The system Calculadora Estatística is a Web-based tool to reinforce learning of statistical techniques, developed by the application of that theory. From a study about humancomputer interaction, its newest version, the Calculadora Estatística Visual, was designed with visual programming features to provide an iconic and flowchart-based interface that allow users visualizing the steps necessary to perform a statistical analysis. It is composed by an interface that works on a statistical package to check users requests in order to guarantee the correctness of the statistical operations sequence.
\end{abstract}

Index Terms - visual tools, web-based learning, statistics.

\section{INTRODUCTION}

Discussions about distance learning are not a novelty and computational tools and Internet-based systems have presented evolutions according to technological advances [1]. These advances changed pedagogical paradigms and added new ways to support students in the learning process by the interactive exposition of subjects able to assist them during the learning process [2].

In that context, the use of images is fundamental and allow developing GUI (Graphical User Interfaces). GUI offer more natural and intuitive environments and use graphical elements to represent operations and components and to present results, among many other functions [4]. Another option allowed by GUI was the development of visual environments. Those environments use the communication capability of images to allow users specifying programs and sequences of steps in a given subject of application. This modality of programming is named Visual Programming. Its main advantage is related to the facility provided to users to memorize information, improving the learning process [3].

Generally, web based systems dedicated to statistical analysis focus on the construction of interactive applications for the development and interpretation of statistical concepts. These systems $\lceil 5\rceil\lceil 6\rceil$ do not have an intelligent architecture to restrict, or even to forbid, the use of sub-routines where per-requirements have not been verified. Direct requisitions in statistical packages execute anything that users demand, as an average of qualitative data. Based on these observations, the Calculadora Estatística was presented in 2005 as a tool to support students in the learning of statistical analysis [71. Some requirements were defined for the Calculadora Estatística implementation [8]:

- Use of a high-level programming language, portable to several operating systems;
- Allows content access through the Web;

- Use of a statistical package that allows expansion;

- Use of a free software with low implementation cost.

The architecture client-server of the system was implemented using the Java language, the software R for statistics calculations and the Rserve package to transmit the commands through the Internet (Figure 1).

The client module of Calculadora Estatística was responsible by verification of users requests in order to check their validity. This request was performed by the interaction of users with buttons present in the interface. Each interaction resulted in a new window opened in which users could select parameters or options related to the operation desired. By the end of this process, users received the result of their request or an warning message pointing out their mistake (Figure 2).

The main problem related to the Calculadora Estatística was the consecutive opening of windows. Since windows were opened, one over the other, it interfered in the visualization of previous selections and steps, as can be observed in Figure 3.

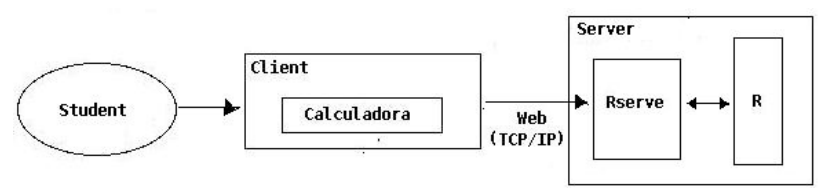

Figure 1. The Calculadora Estatística architecture.

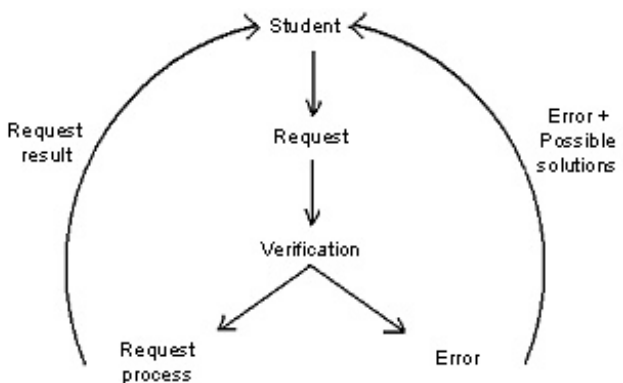

Figure 2. Structure of system interactions in the Calculadora Estatística.

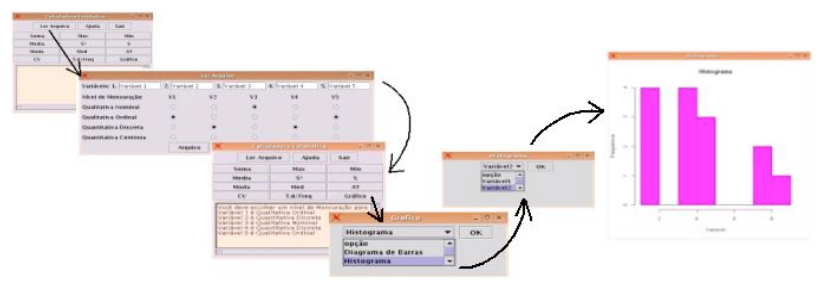

Figure 3. Example of operation using the Calculadora Estatística. 


\section{The Calculadora Estatística Visual}

The Calculadora Estatística Visual is a new development over the Calculadora Estatística. Although it follows the same previous architecture, it improves the client module to provide a visual programming interface in which users can construct requests through flowcharts. This new interface was included in the Client application and replaced the older interface based on windows (Figure 4).

The GUI was divided in 4 main areas: menu bar, flowchart area, tree of modules and output panel (Figure 5). The menu bar has all options and functions of the program and is located in the top of the application window. The flowchart area is the workspace in which the user can compose the flow of operations, inserting boxes and connecting them. At the right side of the window is the tree of modules where the user can check and choose the operations available. The operations are transformed in boxes when moved to the workspace. Then, they can be configured with parameters and input variables. The output panel is used to present the messages of the calculator to the user. In this space can be visualized error messages and execution reports provided by the system. For this area, icons and colors were associated to the messages. Each request in the workspace, e.g. an execute selection in a box, will result in at least one message.

The Constructivist approach was improved with the visual programming interface. This way, the user can observe their own conceptions about statistical analysis in the flowcharts and observe the execution consequences. The messages, icons and object colors were used in the system to help them to think about, fix and learn the correct sequence of a statistical analysis.

Execution requests can change the color of boxes in the workspace indicating success or fail of operations. A success means that the user included previously required operations in the flowchart of an analysis and all were correctly performed. In this case, the system send the operation request to the Statistical Software and displays the result received to the user (Server on Figure 4). When previously required operations are not included in the flowchart or if they present parameters errors, the system provide tips to the user in the output panel in order to help users to identify the problem. The color of boxes with problems is also changed for red in the workspace.

The execution of boxes can be performed individually or in sequence. One sequence is defined from the end to the begin of a continuous connection of boxes and arrows. It means that boxes, even connected, can be out of an execution request if they don't have an arrow directed to the final of the sequence. That is the case of the boxes in the Figure 5, where 3 different sequences are represented. In this figure is possible to observe, in the flowchart area, a mistake made by user in the second sequence. The mistake is highlighted by the red color in the box and explained in the output panel by a message preceded by an error icon, both also in red. In this case, the error was resulted from the choice of a wrong type of random variable which was provided by the database of the previous box (in green). Thus, is possible to see an incorrect request of a sum of qualitative data. In traditional statistical packages this request would be normally processed. In the Calculadora Estatística Visual the requirements are verified prior to the processing request to the statistical package.

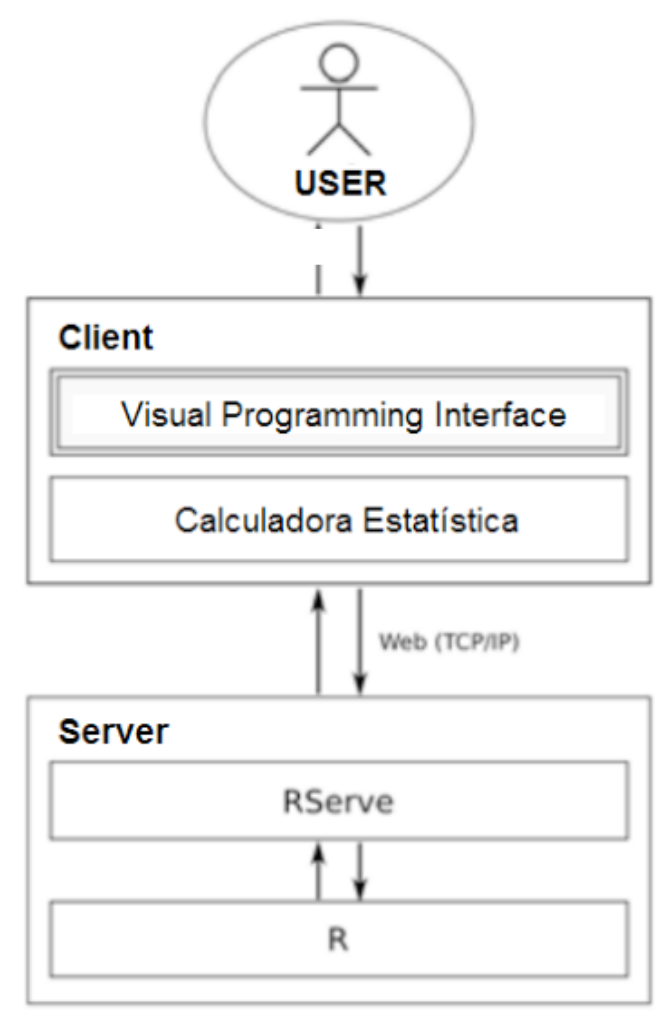

Figure 4. Architecture of the Calculadora Estatística Visual.

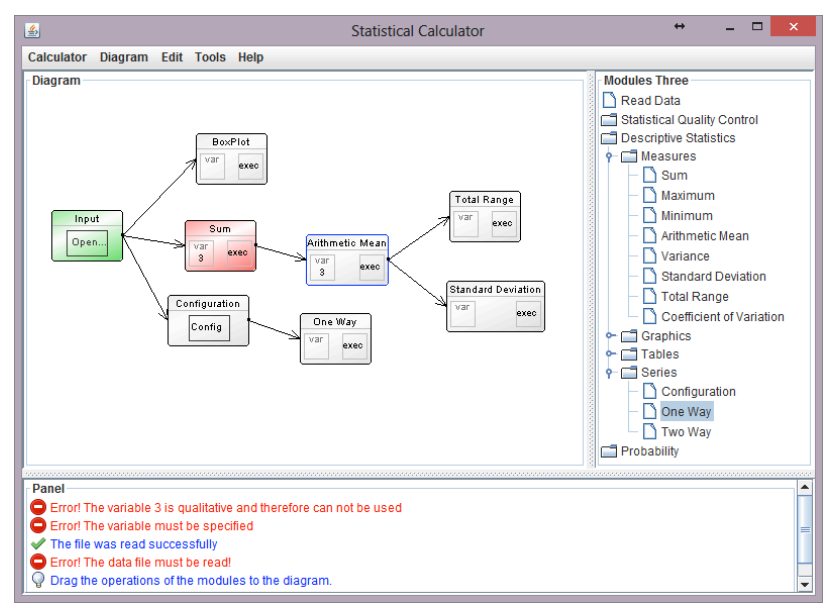

Figure 5. GUI of the Calculadora Estatística Visual.

The modules available in Calculadora Estatística Visual are the same available in the previous Calculadora Estatística:

1. Statistical Quality Control Module

2. Descriptive Statistics Module

3. Probability Module

However, new features were included in the Descriptive Statistical Module and now statistical tables and series are available. Other new features of the system are the choice of interface language and the option to save the diagram for further use.

New modules can be easily included in the system since the architecture is very flexible for that. The main attention in this process must be on the definition of requirements for each operation and on the messages to be provided for the user when they make mistakes. 


\section{CONCLUSION}

The Calculadora Estatística Visual is online and freely available to support the learning of Statistics in the subjects provided by its 3 modules. The system was developed by the Laboratory of Technologies for Virtual Teaching and Statistics (LabTEVE) and can be accessed by the address http://www.de.ufpb.br/ labteve/projects/ calc $\mathrm{v}$ en.html. It is an interactive tool able to assist students in the correct use of statistical techniques. Thus, it can check and advise users about the correct steps of a statistical analysis before send it to a statistical package.

The flexibility of the architecture allows the addition of new modules of statistical operations. Also, other languages can be included in the interface.

\section{REFERENCES}

[1] R. Moraes, L. Machado, "Network Based Education to Statistics Education", Proc. Int. Conference on Information Technology Based Higher Education and Training (ITHET'2001) Kumamoto, Japan, CDROM, 2001.

[2] R. Moraes, J. Zuffo, "An Intelligent Tool for Distance Learning Support", Proc. of 2001 IASTED Int. Conf. on Computers and Advanced Technology in Education (CATE), Banff - Canada, pp. 241-244, 2001.

[3] M. Burnett, M. Baker, Classification System For Visual Programming Languages. Oregon State University, Corvallis, 1994.

[4] C. Digiano, K. Kahn, A. Cypher, D. Smith, "Integrating Learning Supports into the Design of Visual Programming Systems", Journal of Visual Languages and Computing, 12: 501 - 524, 2001. http://dx.doi.org/10.1006/jvlc.2001.0218
[5] J. Banfield, "Web-based Statistical Analysis", Journal of Statistical Software 4(1), 1999.

[6] J. Leeuw, "Server-side Statistics Scripting in PHP", Journal of Statistical Software 2(1), 1997.

[7] R. Gomes, R. Moraes, L. Machado, "An Architecture for Distance Learning to Support Statistics Teaching", Proc. of the 8th IASTED Int. Conf. on Computers and Advanced Technology in Education (CATE), Oranjestad - Aruba. Acta Press, v. 1. pp. 260-265, 2005.

[8] R. Gomes, L. Machado, R. Moraes, "The Calculadora Estatística for Present and Distance Learning”, Proc. of International Conference on Teaching Statistics (ICOTS). Salvador - Brazil. CDROM. 2006.

\section{AUTHORS}

Liliane S. Machado is with the Informatics Department, Federal University of Paraíba in João Pessoa, Brazil (e-mail: liliane@di.ufpb.br).

Ronei M. Moraes is with the Statistics Department, Federal University of Paraíba in João Pessoa, Brazil (email: ronei@de.ufpb.br). He is the head of the Laboratory of Technologies for Virtual Teaching and Statistics (LabTEVE).

Elaine A.M.G. Soares is with the Laboratory of Technologies for Virtual Teaching and Statistics (LabTEVE), Federal University of Paraíba in João Pessoa, Brazil (e-mail: elaineanita1@gmail.com).

This work was supported by the National Counsel of Technological and Scientific Development (CNPq). This article is an extended and modified version of a paper presented at the International Conference exp.at'13, held 18-20 September 2013, in Coimbra, Portugal. Submitted 18 November 2013. Published as re-submitted by the authors 04 December 2013. 